04/07/2005

\title{
Demand for Internet Access and Use in Spain
}

\author{
Leonel Cerno \\ Universidad Europea de Madrid \\ e-mail: leonel.cerno@uem.es
}

\author{
Teodosio Pérez Amaral \\ Universidad Complutense de Madrid \\ e-mail: teodosio@ccee.ucm.es
}

The goal of this paper is to analyze a new phenomenon: Internet demand in Spain. To do so, we use a new high quality data set and advanced econometric techniques for estimating Internet demand functions, incorporating the socio-demographic characteristics of the individuals. We begin with a graphic analysis of the data, searching for relationships between the different characteristics. Then we specify and estimate two econometric models, one for broadband access at home and another for Internet use intensity. We also find that 25.2\% of the Spanish population accesses the Internet at home, but less than half uses broadband connection. This demand is positively related to income and other technological attributes and negatively related to socio-demographic attributes such as habitat and age. Our results are compatible with previous literature for other countries, although there is a important difference: broadband Internet connections are still considered as a luxury good in Spain.

Keywords: Broadband, Internet Access, Internet Use, Selection Bias Correction, Multinomial Logit Models, marginal effects, elasticities.

(JEL C2, C25) 


\section{INTRODUCTION}

Many socio-economic studies of both a theoretical and empirical nature are currently being developed in relation to the phenomenon of Internet service use and high-speed Internet access (called "broadband") in Spain and other countries. If we analyze this phenomenon from a historical perspective in terms of adoption of a new product, the Internet as such is nothing extraordinary. As happens with some new products, Internet demand gradually grew until, in a very short time, it became an indispensable product. Historically, the concept of connecting and using systems in a shared network that allowed for the connection of two computers began to be developed early in the decade of the 60s. It was only in 1969 that the decision was made to implement an experimental network that would make it possible to exchange information between different computers.

Since it is claimed that the Internet phenomenon has changed the habits of families in developed countries, we must ask ourselves what relationships there are with the different factors that lead a family to acquire broadband Internet.

\section{The Case of Spain}

In Spain, there are some early descriptive studies carried out on the basis of independent surveys concerning the adoption of Information Technologies and communications in the country. The National Institute of Statistics (INE) began to compile this information as of 2001. The data in this work were taken from the 2003 INE Survey on Equipment and Use of Information Technologies in the Home (TIC-H).

There is a great variability in access to and use of the Internet. The overall figures contained in Graph 1 show that, while access to the Internet is increasingly common in Spanish homes (25.2\% of all homes), the distribution of this access is not homogeneous.

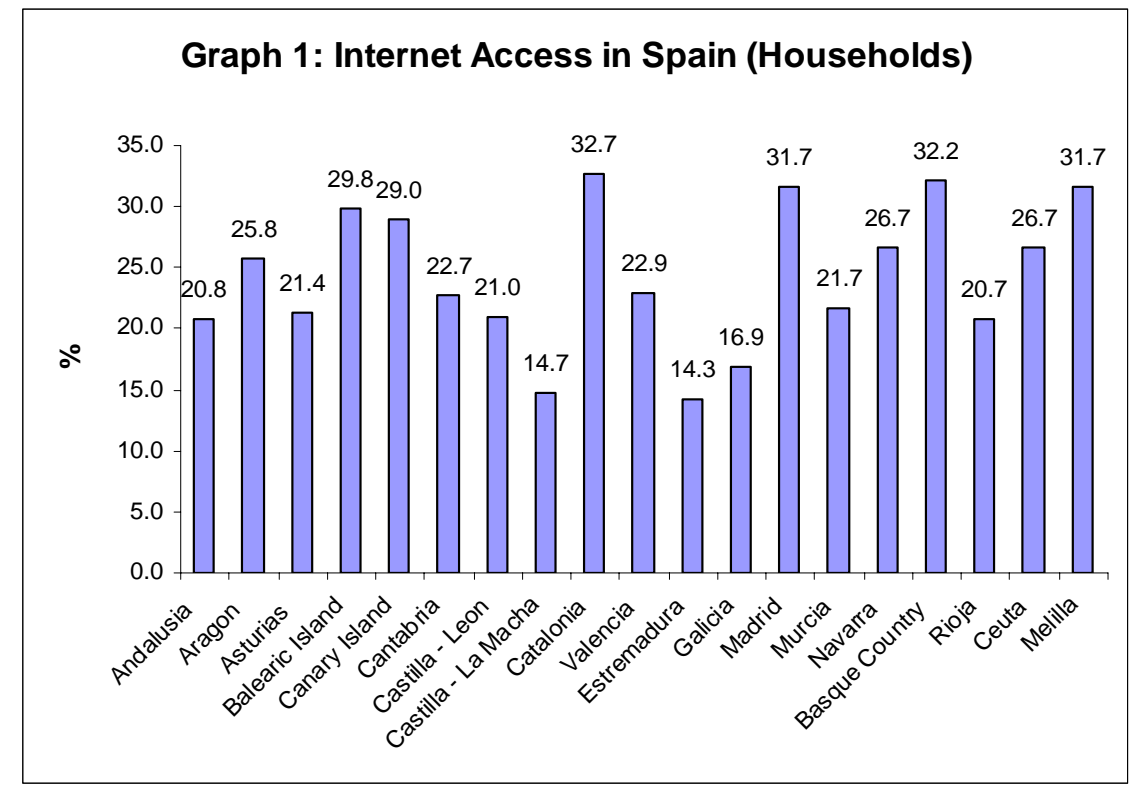

Source: National Institute of Statistics, INE, survey on February 2003, and own elaboration 
This access is more widespread in Catalonia (32.7\%), the Basque Country (32.2\%), Madrid (31.7\%) and Melilla (31.7\%). This contrasts with Estremadura (14.3\%), Castilla-La Mancha (14.7\%) and Galicia (16.9\%).

The main political debate in this area is how to help consumers access the Internet and, in particular, adopt the broadband technology ${ }^{1}$. The debate begins by defining the Internet connection and the broadband technology ${ }^{2}$. For purposes of simplification, we will say that Broadband and High Speed are synonymous.

Rappoport, Kridel and Taylor (2003) clearly establish the existing similarities and differences between the conventional telephone service and adoption of some kind of Internet connection within the demand for telecommunications. What these two types of services have in common is that telecommunications are not consumed in isolation. There is a whole network of productive units involved. Aside from the interdependence and externalities that this situation entails, Access and Use are different concepts. The first and foremost of the differences concerns the measurement of output, since in conventional telephony output is measured in minutes, whereas in the case of the Internet it is measured by speed of file transmission. This leads to the second major difference between these two types of telecommunication services. In the case of some forms of Internet access (such as the cable modem), the speed will be affected by the number of individual Internet access lines that are transmitting at any given time, whereas this does not happen in conventional DSL lines.

This study estimates models of Internet access and use and compares the types of narrowband and broadband connections based on the consumer characteristics contained in a survey carried out by the National Institute of Statistics (INE). These preferences will be considered from two standpoints. On one hand, we will take into consideration the individual conditioned by education, experience and income which, in turn, is conditioned by family size. On the other hand, we will study the demand for the Internet service based on the family group that is demanding it and considering the equipment as indicator of one part of household income.

\section{EARLY STUDIES}

A pioneer econometric study on the adoption of the broadband Internet service is the one by Madden, Savage and Simpson (1996), who examined a database of 5,000 survey responses collected in Australian homes. These authors were the first to discover that demographic characteristics are one of the main influences on the individual decision to use the broadband Internet service. For example, they demonstrate, among other things,

\footnotetext{
${ }^{1}$ The concept of Universal Service Obligation could also include the Internet Service with broadband technology. This involves a different line of research than the one proposed in this article.

${ }^{2}$ Authors such as Owen (2003) believe that it is a true mystery that the debate on the Economics of Broadband has reached the boiling point without yet having agreed on a definition of the term

"Broadband" when there is a complete, accepted list of the services that includes its adoption.
} 
that people who have not finished secondary school show less of an interest in using the broadband Internet service; people who live in homes with at least one native member from Europe or Asia are more interested; age also influences interest depending on whether the individual is younger or older than 65 years of age.

Cassel (1999) uses a survey carried out in 1997 with 30,000 US Consumers. Goolsbee (2000) also examines the demand for Broadband Internet access with data from 100,000 answers to a survey carried out in 1999 in various U.S. cities. Duffy and Deno (2001) study a sample of 11,458 US households. Rappoport, Kridel and Taylor (2002) estimate the broadband Internet demand using a database with demographic information on homes in 10 US cities for 2001.

Other recent studies that make special reference to the Willingness to Pay of Internet users include the one carried out by Varian (2002), which uses data from a University of Berkeley project called "Internet Demand Experiment" and in which he estimates how many people would be willing to pay for different connection speed levels. Different reports have been written in addition to these studies, such as the one released by the U.S. Department of Commerce (2002) that also considers demographic influences on the adoption of Broadband Internet. This study uses the same model as the one proposed by Madden et al. (1996) but for surveys carried out in the United States and considering actual patterns of adoption.

Another report is the one by the Telecommunications Research Group of the University of Colorado (2003), which addresses issues such as how to estimate preferences and profiles of consumers who adopt the Broadband Internet service.

Finally, we should mention the report issued by the OECD (2001) which analyzes the adoption of Wideband Internet connections in 30 countries.

\section{THE DATA}

Our objective is to provide empirical evidence in the debate on Internet access and use, focusing primarily on the form of connection and the user profile. In this study, we use information provided by the Annual Survey TIC - H 2003 carried out by the INE in all of Spain and on two register designs - a family register and another for 10 to 14 year old users. Adoption of a type of Internet connection, the nature of the type of connection and the use that is made of the service would be endogenous in the model proposed in this work.

\section{Internet Access from the Home}

For the first case, there is a sample of 18,949 answers to the question: "do you have some kind of Internet access in the home?”. The frequency distributions are shown in tables and in the appendix; descriptive graphics are provided below. 

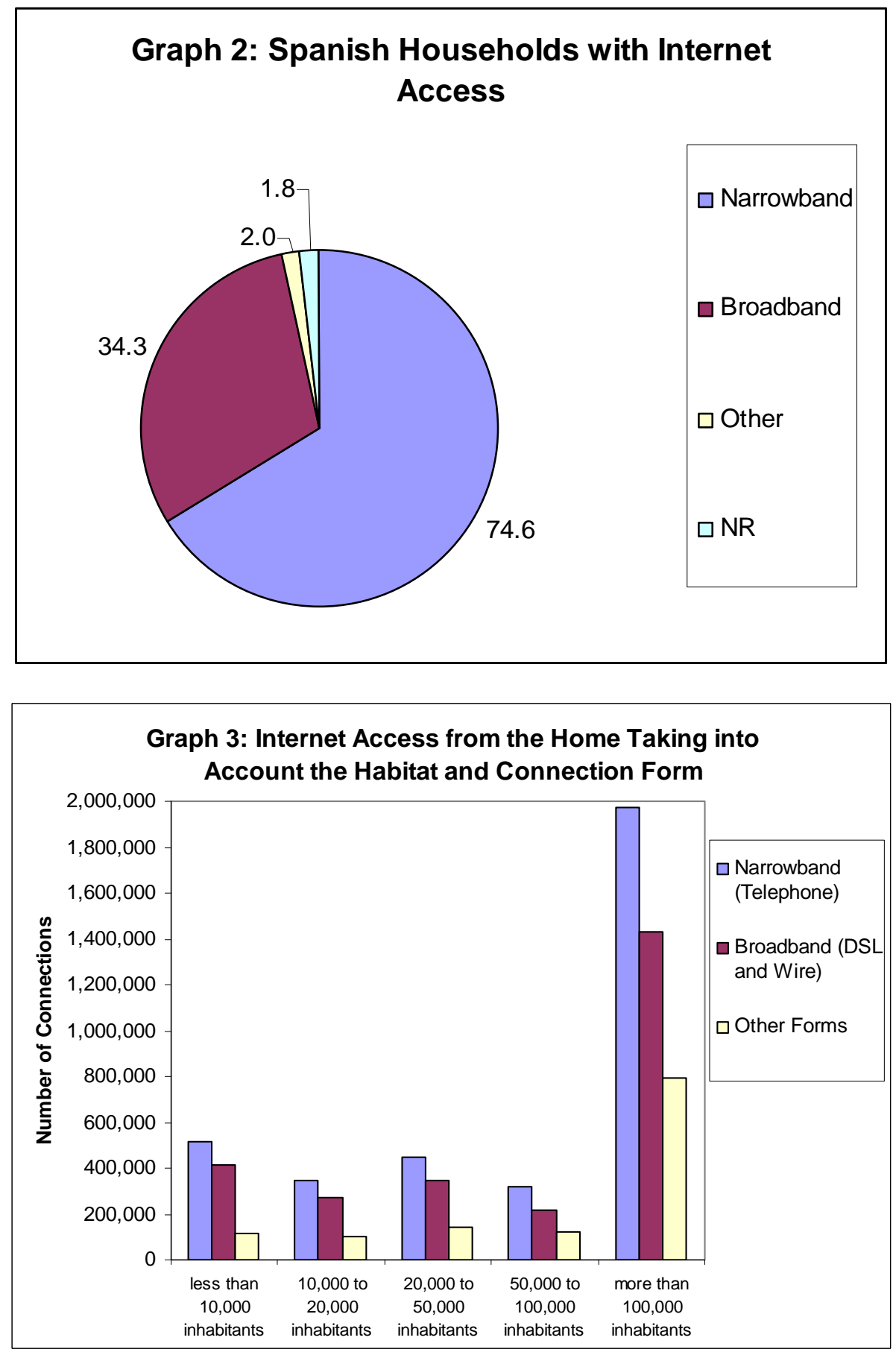

Source: National Institute of Statistics, INE, survey on February 2003, and own elaboration

Graphs 2 and 3, corresponding to Table 1 in the appendix, refer to access to the Internet service from the home, taking into account the habitat where it is located. We see, for example, that of all homes with Internet access (3,599,04 homes), the majority chooses the narrowband form of connection of a conventional telephone line (74.6\%) and only $34.3 \%$ opt for the broadband form of connection or other forms ${ }^{3}$ of connection $(2.0 \%)$. We can see that there are families that choose more than one form of connection because the sum of these percentages does not equal 100 .

\footnotetext{
${ }^{3}$ For example WAP.
} 
The gross data also show that the sample is categorized in accordance with the size of the respondent's home. See Graph 4 below:

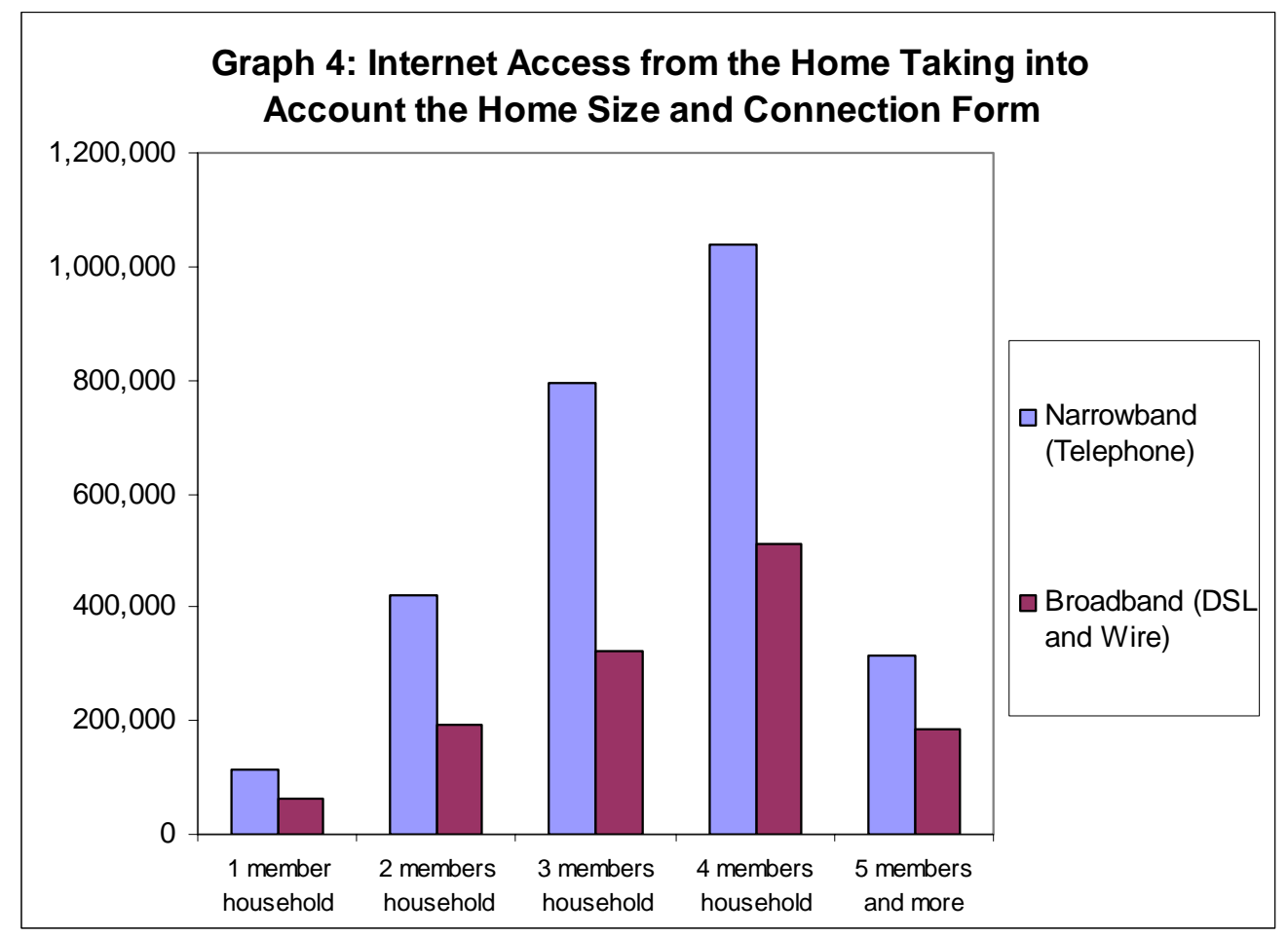

Source: National Institute of Statistics, INE, survey on February 2003, and own elaboration

We can see here that the telephone dial-up connection via modem persists in all the categories considered, with the homes with 4 members prevailing over the rest (40.2\%), especially compared to homes with 1 and 2 members (4.3\% and 15.6\%, respectively). However, we should note that there are considerable differences between the percentages of access via one channel or another depending on the size of the home. This could be explained by the fact that homes with one and two members present two well differentiated typologies: one type of home inhabited by middle-aged or young working people who prefer to access the Internet directly from their workplace instead of from their homes, and another type of home where retired people live. As the latter will have practically no interest in accessing the Internet from their own homes (since they would rely on other centers for this), the average rate of Internet access in general and via a Broadband connection in particular in these one- or two-member homes is less than for homes with more members.

\section{Internet Use}

Graph 5 contains a descriptive analysis of Internet use that relaxes the restriction that access be only from the home. Another thing of note here is that the question is aimed at the individual and not at the home, as it was in the case of access. We can see that of a total of 12,130,100 people who have used the Internet service in the last 3 months, the majority accesses from the home and via one of the types of connection commented on previously. In other words, the majority of the population that uses the Internet (59.7\%) 
does so from the home, followed by those people who connect to the Internet from the workplace (41.3\%), from other places (29.3\%) and from centers of study $(20.4 \%)^{4}$.

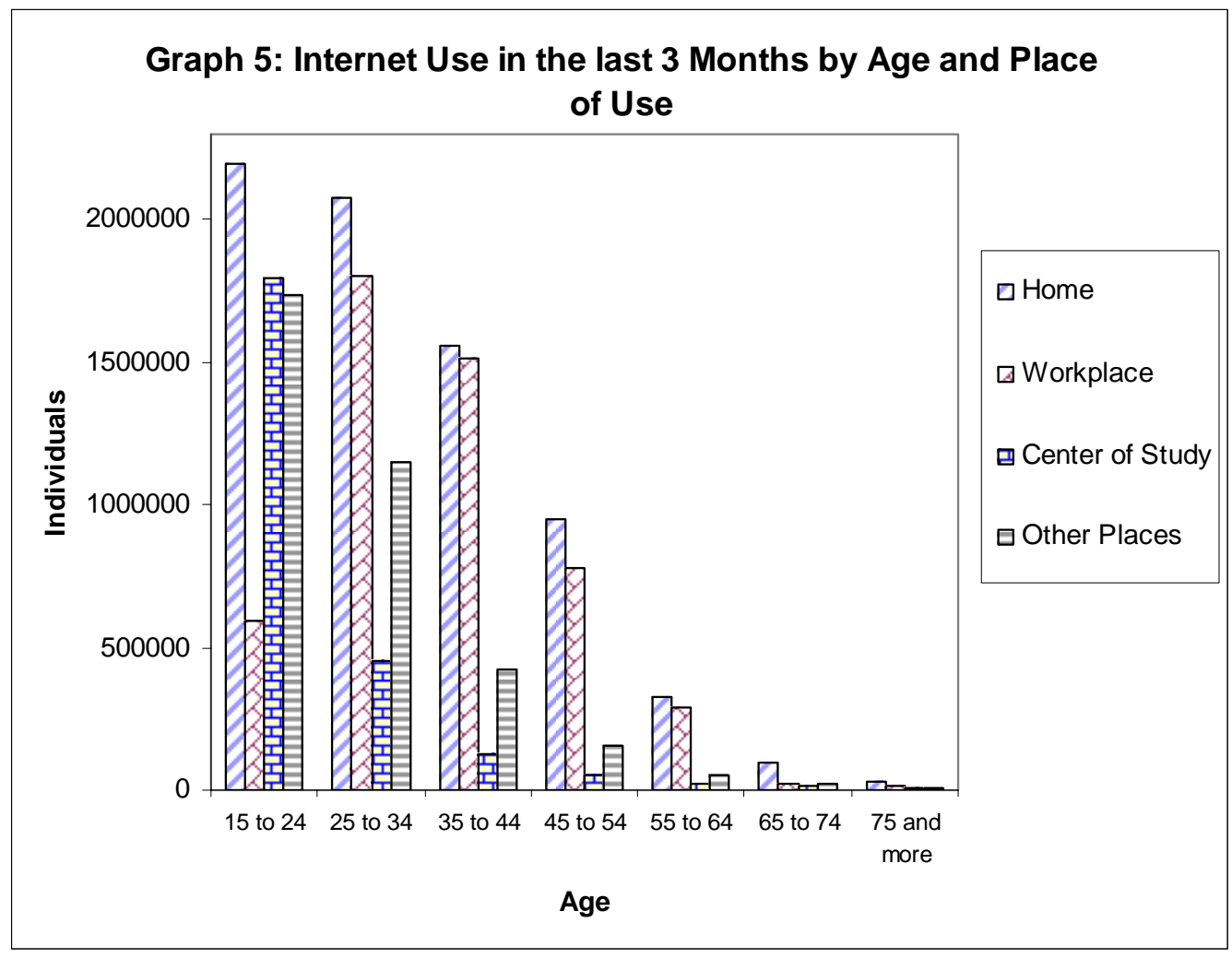

Source: National Institute of Statistics, INE, survey on February 2003, and own elaboration

The place of use illustrates the segmentation of the Spanish population in terms of Internet use. If we observe the graphic, we see that quite a uniform group of all ages uses the Internet from the home, but we also see that younger people (15 to 24 years of age) use it a lot in their centers of study and older people use it a lot from the workplace. Another thing that this graph reveals is that the number of people who connect to the Internet decreases as the age increases, although in relative terms the percentage of people who access the Internet from the home increases (although not observable in the graphic because of the scale used, $72 \%$ of the respondents who are 75 years of age or older accesses the Internet from the home, compared to the respondents in the 15 to 24 years of age interval, with $56.6 \%$ accessing from the home but $46.2 \%$ accessing the Internet from the center of study).

\footnotetext{
${ }^{4}$ The percentages do not add up to 100 because we are considering multiple response tables.
} 


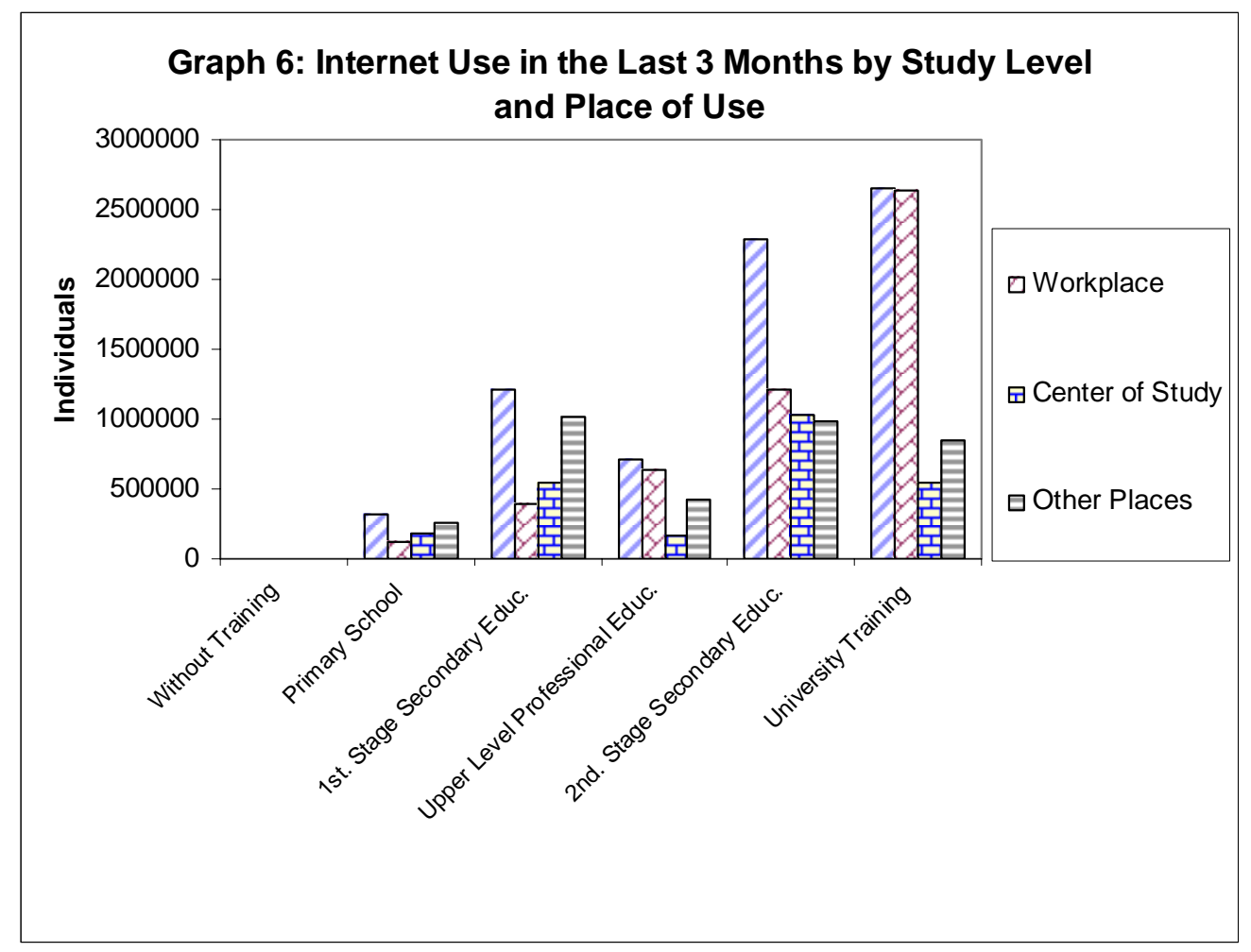

Source: National Institute of Statistics, INE, survey on February 2003, and own elaboration

As regards level of studies, we see from Graph 6 that Internet access will be used to a greater extent by people who have finished upper level studies (33.9\%); they are followed closely by those people who have completed the second stage of secondary education (30.4\%), and then by $19.4 \%$ of people who have completed the first stage of secondary education and $10.6 \%$ of people with upper level Occupational Training. We also see that people with upper level studies will connect a lot from their workplace, while this proportion differs in the other categories under consideration. As is to be expected, people who have completed a level of training other than those mentioned above (except for primary school) and people without any kind of training together represent a mere $0.5 \%$ of the respondents and are barely perceivable in the graphic. It is obvious that the level of education is very much associated with Internet access and use.

Considering next the working and professional status of the respondents, Graph 7 below shows, as expected, that the people who use Internet the most are employed workers who connect to the Internet almost indistinctly from the home and from the workplace (63.83\% in all); they are followed by students (21.20\%) who connect mainly from the center of studies, which is followed closely by access from the home. Unemployed workers account for $6.07 \%$, and the remaining $9 \%$ is divided among people who are not part of the working population (housekeepers, pensioners and unemployed). 


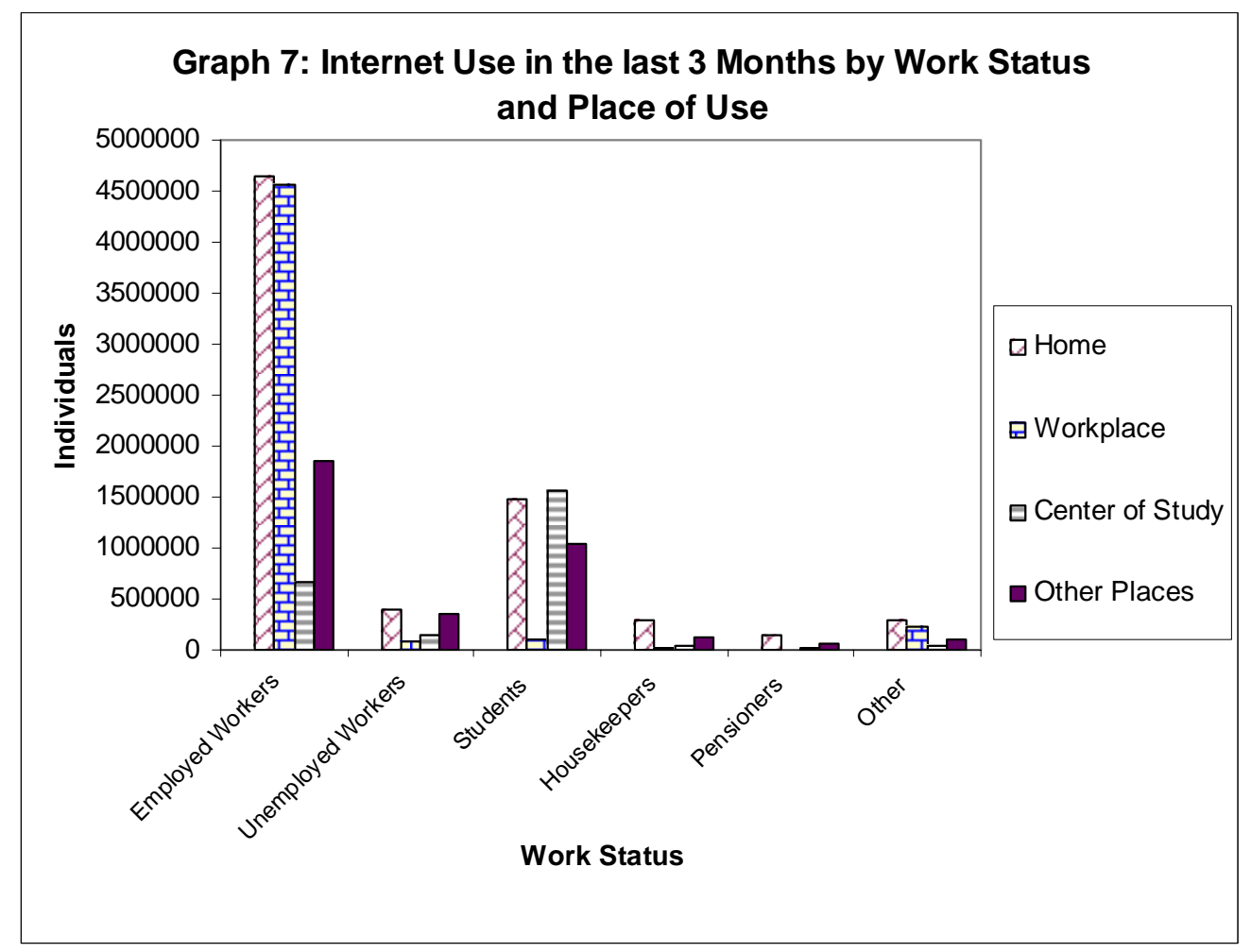

Source: National Institute of Statistics, INE, survey on February 2003, and own elaboration

In general, as we can see, more than half of the people who use the Internet are people whose habitat is in big cities (with more than 100,000 inhabitants) and provincial capitals. In the case of size of the respondent's home, those who use the Internet the most come from three-member homes, followed by those belonging to homes with four or more members, and so on.

After this basic description of the data, we next want to discover and measure the relationships between the variables. We begin by using a demand model that is designed to explain the relationships between the variables of interest.

\section{MODELING HOUSEHOLD ACCESS AND USAGE}

A basic feature in modelling telecommunications demands is the distinction between access and usage. It is obvious that the usage of a given service by an individual is only possible if he/she has access to the service. Usage is conditional on access.

At the same time an individual will choose to join a network only if he/she plans to make some use of it. Access is conditional on use.

This observation is central in the pioneering model of Artle and Averous (1973) and still constitutes a cornerstone for modelling telecommunications demands (Taylor, 1994).

\subsection{Utility Functions}


The theoretical evidence on Internet demand suggests that the Internet is used to save money and time. Following the framework of Taylor $(1994)^{5}$, there are two types of agents:

$G_{0}$ : Subset of agents without access to the net

$G_{1}$ : Subset of agents with access to the net

The utility function of individual $i$ is expressed as

$$
U^{i}=U^{i}\left(x^{i}, \delta^{i} q^{i}\right)
$$

where $x^{i}$ is the vector of the other goods consumed by the $i^{\text {th }}$ agent, and the dichotomous variables determine the access status of the agent, i.e.:

$$
q^{i}\left\{\begin{array} { l } 
{ q \forall i \in G _ { 1 } } \\
{ 0 \forall i \in G _ { 0 } }
\end{array} \quad \delta ^ { i } \left\{\begin{array}{l}
1 \text { if the agent has access (use) } \\
0 \text { otherwise }
\end{array}\right.\right.
$$

The problem of maximizing the utility would then be expressed with individual utility functions for each type of agent as follows:

$$
\begin{array}{ll}
U^{1}=U^{1}\left(x^{1}, q\right) & \text { if } \delta=1 \\
U^{0}=U^{0}\left(x^{0}\right) & \text { if } \delta=0
\end{array}
$$

\subsection{Econometric Approach}

The literature suggests that Internet users differ from other users of telecommunications services in terms of the type of attributes that are relevant. This is supported by Rappoport et al. (2002) when they outline the differences between telephone demand and Internet demand.

In accordance with this, Jackson et al. (2002) use a maximization model of the workleisure choice, assuming that the agents want to have income, leisure time and also online activity.

The theory indicates that maximization of the utility of an agent having access to the Internet in the home is conditioned by the consumption of other goods and the allocation of time and money. A linear approximation of a conditional utility function would be $U_{i}^{*}=x_{i}^{T} \beta+\varepsilon_{i}$, where $U_{i}^{*}$ is the latent utility that agent $i$ experiences on accessing and/or using the Internet, $\beta$ is the vector of parameters to be estimated and represents the vector of the marginal utilities of each of the regressors that are found in the vector $x_{i}^{T}$, and $\varepsilon_{i}$ is an error term.

The parameters of the individual latent utility function (the marginal utilities) are estimated on the basis of information from the responses to the questions posed. In this

\footnotetext{
${ }^{5}$ Taylor summarizes the contributions to the theory of telephone demand from the mid-1970s. Access noaccess plays an important role in the analysis.
} 
paper, we use this framework to analyse the characteristics of Internet users in the case of Spain and to look for relationships that socio-demographic characteristics such as habitat, sex, age, studies completed and others have with the agents that access the Internet from the home or use the net through centers other than the home, e.g. a center of study, workplace, etc. Considering the aforesaid relationship between access and use of the Internet, we can say that a division of the sample of size $N$ is now:

$N_{1}$ : Number of agents with access to Internet from home.

$N_{2}$ : Number of agents with no access from home but with use in other places.

$N_{3}$ : Number of agents without home access and no use.

$N=N_{1}+N_{2}+N_{3}$

We cannot measure directly the utility provided by Internet because that information is not available. We take this into account when we specify the model. We show the decisions of access and use of Internet in Figure 1:

Figure 1: Relationship between Access and Use of Internet

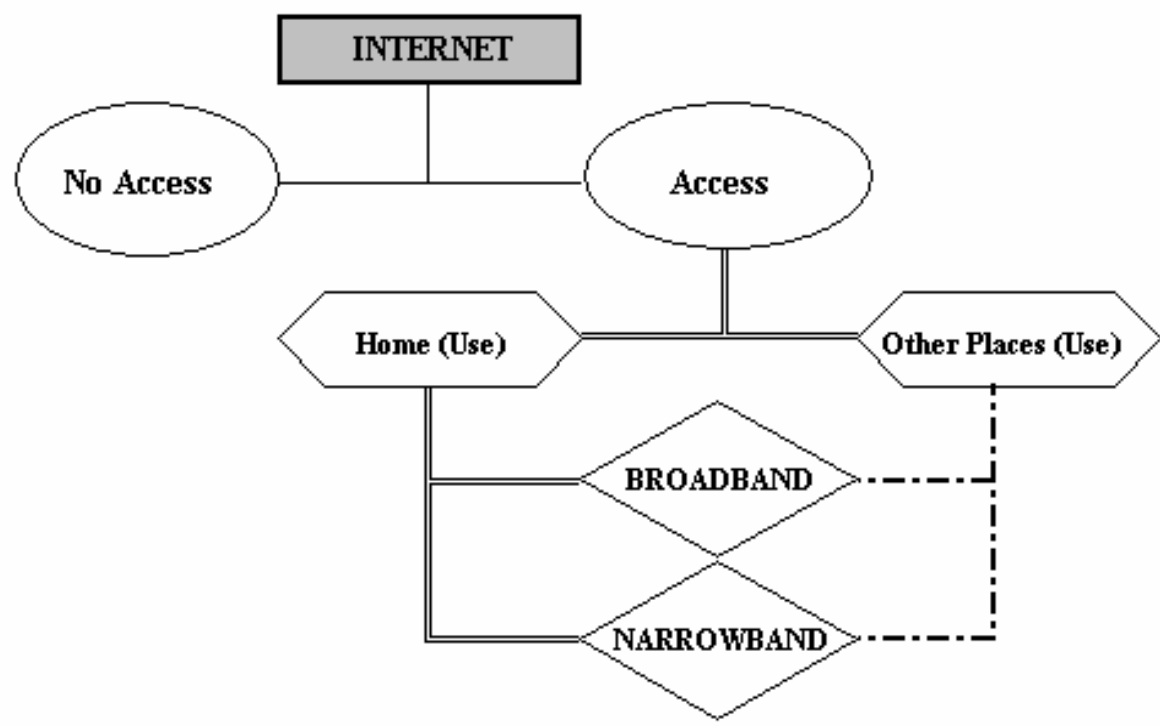

As we can see, Figure 1 suggests that the demand for a given type of connection to Internet occurs if there is a previous choice to access from the home. Starting from there we determine a demand for broadband keeping in mind the following attributes: 


\section{Access to Internet $=\mathbf{f}$ [Economic, Technol., Socio-Demographic Attrib.]}

\section{Use of Internet $\quad=$ g [Economic, Technol., Socio-Demographic Attrib.|Access]}

where each attribute will be quantified as shown below. The model used is based on maximization of the utility of an agent that considers accessing the Internet in a certain scenario.

\subsection{Specification}

Because of the type of data available, we will use a binary probit model with selection bias. Thus, for the first model specified for the $i^{\text {th }}$ individual, we fit two equations and will have both endogenous variables as binary dummies. The endogenous variable of the equation of broadband demand has the following structure

$$
\begin{aligned}
& y_{1 i}^{*}=x_{1 i} \beta_{1}+u_{1 i} \\
& y_{2 i}^{*}=x_{2 i} \beta_{2}+u_{2 i} \\
& y_{1 i}=1 \quad \text { if } y_{1 i}^{*}>0 \quad y_{2 i}=y_{2 i}^{*} \text { if } y_{1 i}^{*}>0 \\
& y_{2 i}=0 \quad \text { if } y_{1 i}^{*}<0 \quad y_{2 i}=0 \quad \text { if } y_{1 i}^{*}>0
\end{aligned}
$$

and is referred to the type of Internet connection at home ( $y_{2 i}=1$ if it has broadband), but it only makes sense when variable $y_{1 i}=1$, i.e. has Internet at home. This means that the variable $y_{1 i}$ non-randomly selects the sample for estimating a demand model to measure the effects on the type of Internet connection at home. The regressors are explained in the following Table:

Table 1. Regressors

\begin{tabular}{ll}
\hline \hline Variable Name & Definition \\
\hline \hline $\begin{array}{c}\text { Economic } \\
\text { o income }\end{array}$ & Family income index. \\
\hline \hline Technologic & $=1$, if there is a PC at home; $=0$ otherwise \\
o pc & $=1$, if a laptop is owned; $=0$ otherwise
\end{tabular}


o mobile $\quad=1$, if a household member has a mobile phone; $=0$ otherwise

o frequser Internet use (quarterly number of times $=70,14,3,1,0$ )

o usagecomp Computer use (number of times per quarter $=70,14,3,1,0$ )

o broadband $\quad=1$, broadband Internet connection at home; $=0$ otherwise

Social and Demographic

o bestudying $\quad=1$, if the respondent is studying; =0 otherwise

o studylevel Degree achieved in studies (measured by years of study).

o housemembers Number of residents in the household

o habitat Population size

o male $=1$, if the respondent is male; $=0$ otherwise

o age Age of the respondent

o agesq Square of age of the respondent

We approximate the demand for broadband access as:

$y_{2 i}=\beta_{0}+\beta_{1}$ income $_{i}+\beta_{2} p c_{i}+\beta_{3}$ laptop $_{i}+\beta_{4}$ mobile $_{i}+\beta_{5}$ frequser $_{i}+\beta_{6}$ bestudying $_{i}+$ $+\beta_{7}$ housemembers $_{i}+\beta_{8}$ habitat $_{i}+\beta_{9}$ male $_{i}+\beta_{10}$ age $_{i}+\beta_{11}$ agesq $_{i}+\operatorname{IMR}(x)_{i}+\varepsilon_{i}$ $i=1, \ldots, 18,948$.

where $\operatorname{IMR}(x)=\frac{\phi\left(z^{T} \gamma\right)}{\left[1-\Phi\left(z^{T} \gamma\right)\right]}$ is the inverse of the Mills ratio; it is then added as a regressor for correcting the sample selection bias. The endogenous variable $y_{2 i}$ is a binary variable and represents the output of the indicator function referred to the individual who has broadband Internet at home (that is, equal to 1 if the individual has broadband at home and 0 otherwise).

\section{ESTIMATION AND DISCUSSION}


The endogenous variable in the outcome equation is having or not having broadband access at the home. As noted earlier, the marginal effect on $y_{2 i}$ is composed of the effect of the selection equation and the outcome equation. In other words, every predictor in the model may appear not only as a exogenous variable in the outcome equation, but also as a component of $\operatorname{IMR}(x)$. One consequence of this is that the effect on $n$ units of change in the vector of the exogenous variables is not simply $n$ times the effect of one unit of change in this vector. This means that the change in the endogenous variable depends not only on the magnitude of the change, but also on the base from which the change takes place (Sigelman and Zeng, 1999).

\section{Subscription to Broadband Access at Home Model Results}

Table 2 below shows the estimation results of the first fitted model specified in equation (1.7). This estimation has been a binary probit model with a selection bias. We observe first that to be currently studying, the number of members in the home and being male are insignificant. However, the signs of the coefficients of the significant variables are as expected, since income, having a computer at home and frequent use of the Internet have a positive relationship with the probability of having broadband service at home. However, it decreases with increasing age and with habitat size. Taking into account only the significant variables, we highlight the following points:

Table 2: Demand for Broadband at Home: Estimation Results of the Probit Model

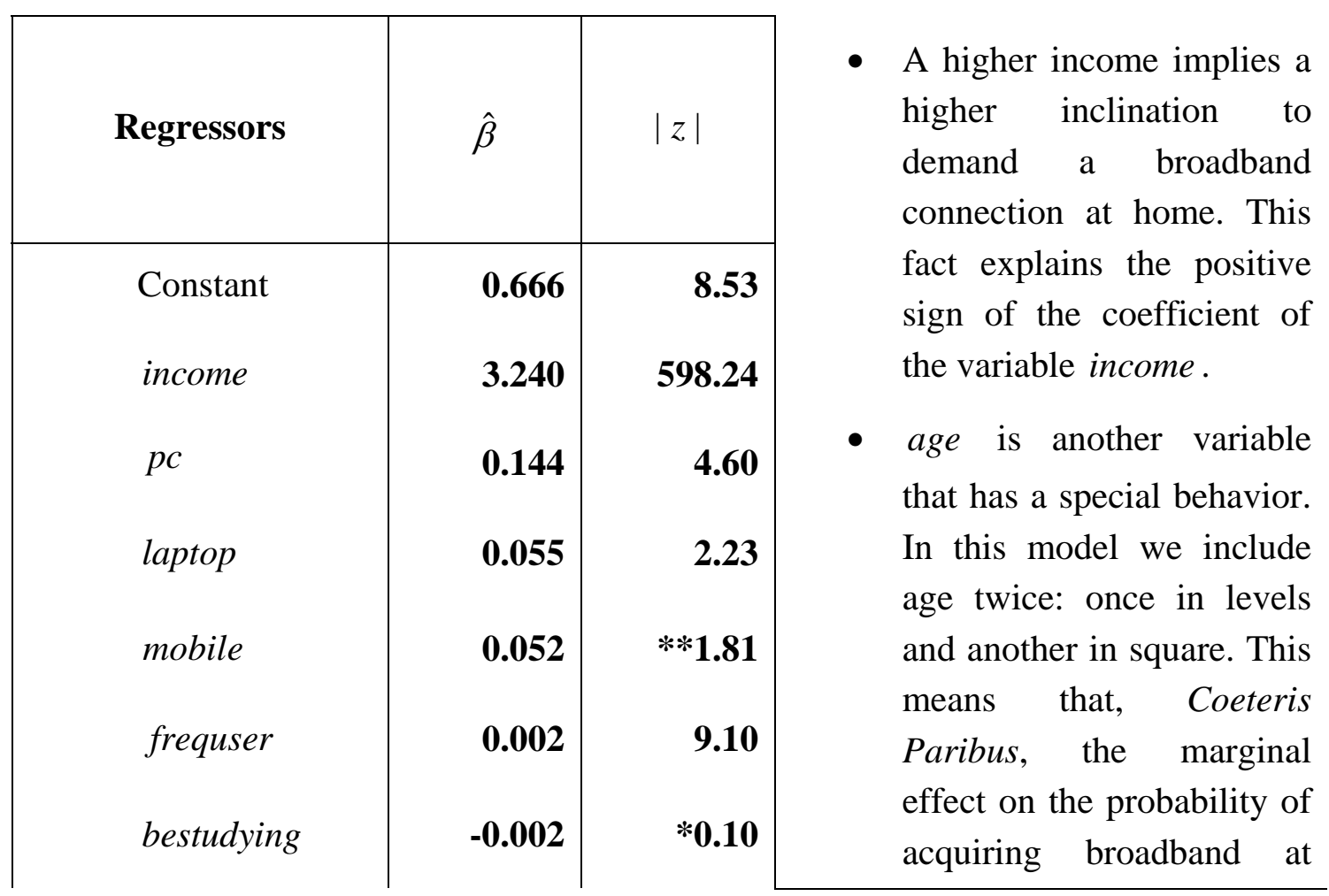




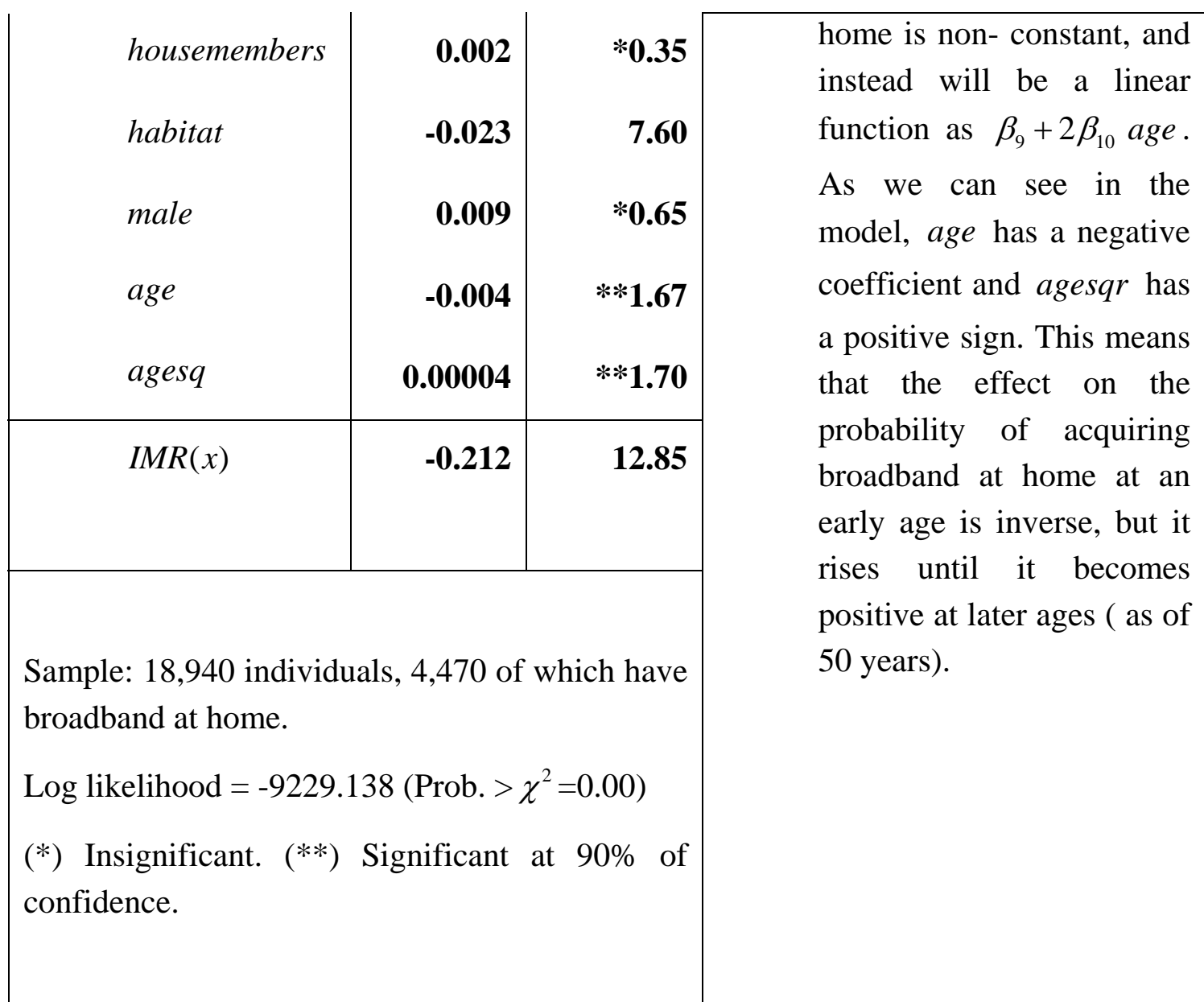

- The technological attributes have a positive role in the probability of demanding domestic broadband. If people want access to Internet at home, it is necessary to have a PC or laptop. Even so, we see that the variable mobile also has a positive effect on the probability of demanding broadband and of using Internet frequently ( frequser ).

- The size of the habitat has a negative coefficient, and this means a negative influence on the probability of broadband at home. This fact could be explained by the fact that, in big cities, there are more possibilities of access than in little cities or towns, i.e. through cyber-cafes, municipal points, booths, etc.

\section{Internet Use Model and Results}

Next we specify a second model referred to Internet use given that it is possible to access from: home, workplace, center of study and other places such as hotels, cybercafés, etc.

We specify a multinomial logit in which we consider the use of Internet and its determinants from the home, the worksite, the place of study and other places (hotels, 
cyber-cafés, airports, booths, etc) ${ }^{6}$. The explanatory variables that we use, although they are not exactly the same ones, follow the same philosophy of considering economic, technological and socio-demographic attributes. The dependent variable is a politomic variable referred to the use of Internet in the four mentioned places. That is,

$$
U S E_{j}\left\{\begin{array}{l}
=1 \text { if Internet is used in one of the places considered } \\
=2 \text { if uses in two places } \\
=3 \text { if uses in three places } \\
=4 \text { uses in the four places considered }
\end{array}\right.
$$

The multinomial logit will be equivalent to:

$$
\ln \frac{P_{i j}}{\left(1-P_{i j}\right)}=x_{i}^{T} \beta_{j} \quad j=1,2,3,4 .
$$

where $P_{i 1}, P_{i 2}, P_{i 3}$ and $P_{i 4}$ are the probabilities of use of Internet in one, two, three and four places considered. The $x_{i}^{T}$ is a vector of regressors of $i$, and $\beta$ is a vector of parameters. As we saw above in the first graphical analysis, the most frequent place of use is the home, followed by the workplace and the place of study. Indeed, we have a multinomial logit with an endogenous variable with four categories, one that will be equal to one if Internet is used in only one of the four places (may be at home), another that will be equal to two if used in two places (may also be at work or school), and three or four if used in almost all or all of the places considered, respectively. Furthermore, these places of use are not mutually excluding. The results can be seen in following Table 3.

\begin{tabular}{|c|c|c|c|c|}
\hline Regressors & $U S E=1$ & $U S E=2$ & $U S E=3$ & $U S E=4$ \\
\hline \multirow[t]{2}{*}{ Constant } & -3.80 & -6.57 & -9.45 & -14.29 \\
\hline & (20.09) & (26.54) & (18.90) & (10.46) \\
\hline \multirow[t]{2}{*}{ income } & 11.84 & 21.23 & 24.98 & 38.87 \\
\hline & (16.10) & (21.88) & (13.30) & ( 7.86) \\
\hline \multirow[t]{2}{*}{ broadband } & 1.44 & 1.74 & 2.04 & 2.09 \\
\hline & (15.01) & (16.75) & (13.06) & (6.19) \\
\hline \multirow[t]{2}{*}{ usagecomp } & 1.06 & 0.75 & 0.44 & 0.41 \\
\hline & (37.08) & (19.69) & (5.01) & $(1.59)^{*}$ \\
\hline bestudying & 0.83 & 1.51 & 2.29 & 2.88 \\
\hline
\end{tabular}

Table 3: Demand of Internet Use, Results of Estimations

\footnotetext{
${ }^{6}$ See Sigelman and Zeng (1999); compare with Rappoport, Kridel and Taylor (2003).
} 


\begin{tabular}{|c|c|c|c|c|}
\hline \multirow[b]{2}{*}{ studylevel } & (10.55) & $(17.20)$ & (6.19) & (7.81) \\
\hline & $\begin{array}{l}-2.51 \\
(6.19)\end{array}$ & $\begin{array}{l}-5.46 \\
(10.54)\end{array}$ & $\begin{array}{l}-6.07 \\
(6.08)\end{array}$ & $\begin{array}{l}-12.65 \\
(4.85)\end{array}$ \\
\hline housemembers & $\begin{array}{l}-0.20 \\
(7.96)\end{array}$ & $\begin{array}{l}-0.20 \\
(6.57)\end{array}$ & $\begin{array}{l}-0.26 \\
(4.53)\end{array}$ & $\begin{array}{l}-0.28 \\
(2.00)\end{array}$ \\
\hline habitat & $\begin{array}{l}0.15 * \\
(1.19)\end{array}$ & $\begin{array}{l}0.02 * \\
(1.37)\end{array}$ & $\begin{array}{l}0.06 * * \\
(2.29)\end{array}$ & $\begin{array}{l}0.04^{* *} \\
(0.59)\end{array}$ \\
\hline \multirow[t]{2}{*}{ male } & $\begin{array}{l}0.41 \\
(7.38)\end{array}$ & $\begin{array}{l}0.58 \\
(8.59)\end{array}$ & $\begin{array}{l}0.88 \\
(6.88)\end{array}$ & $\begin{array}{l}0.90 \\
(2.81)\end{array}$ \\
\hline & $\begin{array}{l}-0.05 \\
(21.68)\end{array}$ & $\begin{array}{l}-0.06 \\
(20.83)\end{array}$ & $\begin{array}{l}-0.08 \\
(12.83)\end{array}$ & $\begin{array}{l}-0.09 \\
(5.13)\end{array}$ \\
\hline \multicolumn{5}{|l|}{$\begin{array}{l}\text { Total of Observations: } 18,940 \\
\text { Log likelihood }=-9115.67\left(\text { Prob }>\chi^{2}=0.00\right)\end{array}$} \\
\hline
\end{tabular}

$t$ statistics in parentheses. $(*)$ Insignificant. (**) Significant with 95\% of confidence level.

In this second estimation we see that estimation of the coefficients appears differentiated, in general increasing in absolute value from left to right. This means that the use of Internet is directly proportional to the economic, technologic and socio demographic attributes, in accordance with the results found in the literature. $\hat{\beta}_{3}$, the coefficient of habitat, is insignificant except for $U S E=3$, while the meaning of the rest of the variables is clear. The variables that separate the profile of an intense user from that of a light user are: age, income and both technological attributes: broadband at home and computer use.

For those that use Internet from several places (e.g.: USE $=3$ and USE $=4$ ), the profiles are better explained by the income, having broadband at home (measured through broadband) and age. Notice that for heavy users, their profiles will be explained better by income, and we think this makes sense because if the user has the possibility of accessing Internet from some places, such as the workplace or the center of studies, for free, the user would also purchase a broadband connection from home only if she/he had a high income.

These results agree with those of the previous model and ratify the fact that in Spain the broadband connection at home is still considered a luxury good. See the following Table . 


\section{Marginal Effects and Elasticities}

Now we center on the analysis of the marginal effects and elasticities of the two models. They are shown in Tables 5 and 6:

Table 5. Marginal Effects of the First Model (Internet Access in Home)

$$
y=E\left[y_{i} \mid \operatorname{Pr}\left(z_{i}>0\right)\right]=0.02377
$$

\begin{tabular}{|l|c|c|}
\hline \hline Variable & $\frac{d y}{d x}$ & Mean \\
\hline income & $\mathbf{0 . 2 4 0 7}$ & $\mathbf{0 . 3 8 2 5}$ \\
\hline$p c$ & $\mathbf{0 . 0 3 6 9}$ & $\mathbf{0 . 2 2 1 4}$ \\
\hline laptop & $\mathbf{0 . 0 2 3 3}$ & $\mathbf{0 . 0 2 9 0}$ \\
mobile & $\mathbf{0 . 0 1 1 2}$ & $\mathbf{0 . 0 1 4 9}$ \\
usagin & $\mathbf{0 . 0 9 9 0}$ & $\mathbf{0 . 5 0 9 5}$ \\
\hline bestudying & $\mathbf{0 . 0 0 2 4 *}$ & $\mathbf{0 . 1 2 0 1}$ \\
housemembers & $\mathbf{0 . 0 0 1 0 *}$ & 2.8789 \\
habitat & $\mathbf{- 0 . 0 0 4 1}$ & $\mathbf{4 . 2 9 5 4}$ \\
male & $\mathbf{0 . 0 0 5 0 *}$ & $\mathbf{0 . 4 3 5 7}$ \\
age & $\mathbf{- 0 . 0 0 1 1}$ & $\mathbf{4 9 . 8 6 8 8}$ \\
agesq & $\mathbf{0 . 0 0 0 0 1}$ & $\mathbf{2 8 7 8 . 0 4}$ \\
\hline \hline
\end{tabular}

\section{(*) Insignificant}

With regard to income, this is the variable that most increases the probability with 0.2407. This confirms the first results in the estimation.

The technological attributes, as is obvious, also increase the probability of acquiring a broadband connection at home. Their coefficients are 0.0369, 0.0233, 0.0112 and 0.099 , respectively, corresponding to having a PC, a laptop, a mobile connection to Internet or using Internet frequently.

With regards to the habitat and age, both are related to a decrease in the probability of demanding broadband from home of 0.0041 and 0.011 , respectively. 
Table 6: Marginal Effects of the Internet Use Model

\begin{tabular}{|c|c|c|c|c|c|}
\hline \multicolumn{6}{|c|}{$y=\operatorname{Pr}($ use $=j)$} \\
\hline Variable & 0.0704 & 0.0159 & 0.0010 & 0.00003 & Mean \\
\hline income & 0.7491 & 0.3193 & 0.0237 & $0.0013^{*}$ & 0.3845 \\
\hline broadband & 0.1457 & 0.0486 & 0.0043 & 0.0002 & 0.0811 \\
\hline usagecomp & 0.0686 & 0.0105 & 0.0004 & 0.00001 & 0.5773 \\
\hline bestudying & 0.0652 & 0.0400 & 0.0059 & 0.0004 & 0.1204 \\
\hline studylevel & -0.1574 & -0.0828 & -0.0058 & $-0.0004^{*}$ & 0.5525 \\
\hline housemembers & -0.0128 & -0.0029 & -0.0002 & $-8.92 e-06$ & 2.8805 \\
\hline habitat & $0.0010 *$ & $0.0003^{*}$ & 0.00006 & $1.27 \mathrm{e}-06$ & 4.2962 \\
\hline male & 0.0267 & 0.0091 & 0.0009 & 0.00003 & 0.4356 \\
\hline age & -0.0031 & -0.0009 & -0.00008 & $-2.86 e-06 *$ & 49.845 \\
\hline
\end{tabular}

(*) Insignificant

In this next table, we see that in the first row there are the probabilities of Internet use in one place (0.0704), in two places (0.0159), in three places (0.0010) and in four places (0.00003). The signs of the estimates are the same in every category of the endogenous variable, and in general the effects decrease as the number of places of use increases. For example, the influence of the "income" coefficient on the probability of use decreases as the influence of places increases ( 0.7491 for one place, 0.3193 for two and 0.0237 for three places).

Of note regarding the variable referred to "study level" is its negative sign in all categories of the endogenous variable. This can be explained by the correlation that it has with age (i.e, the higher the study level, the higher the age). This does not occur when we consider the aspect of currently studying (measured for the coefficients of the variable bestudying ).

With respect to elasticities of the variables, "income" and "age", the results are shown in the following table:

Table 7. Elasticities with respect to Income and Age in the Demand For Access and Use of Internet 


\begin{tabular}{|c|c|c|c|c|c|}
\hline & \multirow[t]{2}{*}{ Access } & \multicolumn{4}{|c|}{ Use } \\
\hline & & 1 & 2 & 3 & 4 \\
\hline income & 1.1454 & 0.6986 & 0.2978 & 0.0221 & Insignificant \\
\hline age & -0.6789 & -0.3748 & -0.1088 & -0.0097 & Insignificant \\
\hline
\end{tabular}

We see first that the elasticity with respect to "income" is positive and the elasticity to "age" is negative. Furthermore, the demand for access at home is elastic with respect to income, but it will be inelastic in the case of demand for use.

The percentage increase of "income" raises the use less than proportionally in all the categories of the endogenous variable. This will decrease as the places of use increase, in line with the results obtained in the estimation and in the marginal effects.

Another result is the effect of "age". This effect will diminish with the use of Internet, even though the decrease will be smaller as the number of places of use increases.

\section{CONCLUSIONS AND FUTURE RESEARCH}

Our intention in this work is to analyze the demand for Internet from home in Spain. We use the framework provided in the literature on the residential consumer of Internet access. We estimate the demand for the use of this service at home and also consider Internet use in other places besides the home.

In the first step, we describe what characteristics may affect the access and use of Internet, with a comparative analysis between the user typologies and the type of connection. First we find that $25.2 \%$ of the Spanish population accesses the Internet, but less than half uses broadband connections (35.5\% of Internet connections). These percentages vary considerably by region. Furthermore, we observe relationships between the social and demographic characteristics and Internet use similar to those described in the literature for other countries.

Then we specify and estimate a demand for broadband access from home through the two-step probit model with correction of the selectivity bias (Heckman, 1979), and confirm that demand for the Internet service is positively related to income and the technological attributes and negatively related to socio-demographic attributes such as habitat and age. These results are consistent with the literature for other countries.

Then we estimate a model of demand for use of Internet taking into account the number of places of Internet use (four in all). We see that the effects of the three attributes are in general directly proportional to Internet use. The quantification of the 
income and age effect to define user profiles, the marginal effects and the calculated elasticities demonstrate that broadband access at home is still considered a luxury good, but the use of this service can almost be considered as a necessity.

In future research, it would be useful to have data on personal income and on the service prices in order to estimate a broadband demand function for different regions of Spain. Also, it would be useful to have more comprehensive information on individuals and to work with panels of individuals over several periods, in order to evaluate the dynamics affecting the demand for the Internet service in Spain.

\section{REFERENCES}

1. Artle, R. and Averous, C. "The Telephone System as a Public Good: Static and Dynamic Aspects” Bell Journal of Economics and Management Science, Vol. 4, No. 1, 89-100, spring 1973.

2. Cassel, C., "Demand for and Use of Additional Lines by Residential Customers”, in Loomis and Taylor (eds.) The Future of the Telecommunications Industry: Forecasting and Demand Analysis, Kluwer Academic Publishers, Boston, 1999.

3. Davidson, R. and MacKinnon, J., "Econometric Theory and Methods" Oxford University Press, 1993.

4. Duffy-Deno, K. T. "Demand for Additional Telephone Lines: An Empirical Note”, Information Economics and Policy, 13, 301-309, 2001.

5. Friedman, M. “A Theory of the Consumption Function”, Princeton University Press for the National Bureau of Economic Research, 1957.

6. Goodman, A. and Kawai, M. "Permanent Income, Hedonic Price and Demand for Housing: New Evidence”, Journal of Urban Economics, 12, 214-237, 1982.

7. Goolsbee, A. "The Value of Broadband and the Deadweight Loss of Taxing New Technology”, Mimeo, University of Chicago, 2000.

8. Heckman, J. "Sample Selection Bias as a Specification Error" Econometrica, Vol. 47, No. 1, January 1979.

9. Jackson, M., Lookabaugh, T., Savage, S., Sicker, D. and Waldman, D. "Broadband Demand Study: Final Report" Telecommunications Research Group, University of Colorado, 2003.

10. Madden, G. and Coble-Neal, G., “Australian Residential Telecommunications Consumption and Substitution Patterns" preliminary draft, $15^{\text {th }}$ International Telecommunications Society Meeting, Berlin, Germany, 4-7 September 2004. 
11. Madden, G., Savage, S. and Simpson, M. "Information Inequality and Broadband Network Access: An Analysis of Australian Household Survey Data” Industry and Corporate Change, Oxford University Press, 1049-1056, 1996.

12. Mc Fadden, D. "Conditional Logit Analysis of Qualitative Choice Behavior” in Zarembka (ed.) Frontiers in Econometrics, Academic Press, pp. 1117-1156, 1974.

13. Mc Fadden, D. “Econometric Analysis of Qualitative Response Models” in Z. Grilliches and M. Intriligator (eds.) Handbook of Econometrics, Amsterdam, North Holland, pp. 1376-1425, 1984.

14. Meng, C. and Schmidt, P. "On the Cost of Partial Observability in the Bivariate Probit Model” International Economic Review, Vol. 26, No. 1, February 1985.

15. Organization for Economic Cooperation and Development, “The Development of Broadband in OEDC Countries”, October 29, 2001.

16. Owen, B. "Broadband Mysteries" in Crandall, R. and Alleman, J. (ed.) Broadband: Should we Regulate High-speed Internet Access? AEI - Brookings Joint Center for Regulatory Studies, 2002.

17. Pérez Amaral, T., F. Alvarez and B. Moreno "Business Telephone Traffic Demand in Spain 1980-1991: an Econometric Approach”, Information Economics and Policy, 7, 115-134, 1995.

18. Rappoport P., Taylor L., and Kridel D. "The Demand of Broadband: Access, Content, and the Value of Time”, in Broadband: Should We Regulate HighSpeed Internet Access?, ed. by R. W. Crandall and J. H. Alleman, AEIBrookings Joint Centre for Regulatory Studies, Washington, D.C., 2003.

19. Sigelman, L. and Zeng, L. “Analyzing Censored and Sample-Selected Data with Tobit and Heckit Models” Political Analysis, 8:2, The George Washington University Working Papers, December 16, 1999.

20. Taylor, L. D. "Towards a framework for analyzing internet demand", Manuscript, U. of Arizona, 2000.

21. Taylor, L. D. “Telecommunications Demand in Theory and Practice” Kluwer Academic Publishers, 1993.

22. U.S. Department of Commerce, and National Telecommunications \& Information Administration, “A Nation Online: How Americans Are Expanding Their Use of the Internet”, February 2002.

23. Varian, H. "The Demand for Bandwidth: Evidence from the INDEX Project”, Mimeo, University of California, Berkeley, 2002. 